\title{
INVERSION FOR SLIP DISTRIBUTION USING TELESEISMIC $P$ WAVEFORMS: NORTH PALM SPRINGS, BORAH PEAK, AND MICHOACAN EARTHQUAKES
}

By Carlos Mendoza and Stephen H. Hartzell

\begin{abstract}
We have inverted the teleseismic $P$ waveforms recorded by stations of the Global Digital Seismograph Network for the 8 July 1986 North Palm Springs, California, the 28 October 1983 Borah Peak, Idaho, and the 19 September 1985 Michoacan, Mexico, earthquakes to recover the distribution of slip on each of the faults using a point-by-point inversion method with smoothing and positivity constraints. In the inversion procedure, a fault plane with fixed strike and dip is placed in the region of the earthquake hypocenter and divided into a large number of subfaults. Rupture is assumed to propagate at a constant velocity away from the hypocenter, and synthetic ground motions for pure strike-slip and dip-slip dislocations are calculated at the teleseismic stations for each subfault. The observed seismograms are then inverted to obtain the distribution of strike-slip and dip-slip displacement for the earthquake.

Results of the inversion indicate that the Global Digital Seismograph Network data are useful for deriving fault dislocation models for moderate to large events. However, a wide range of frequencies, which includes periods shorter than those within the passband of the long-period Global Digital Seismograph Network instruments, is necessary to infer the distribution of slip on the earthquake fault. Although the long-period waveforms define the size (dimensions and seismic moment) of the earthquake, data at shorter periods provide additional constraints on the variation of slip on the fault. Dislocation models obtained for all three earthquakes are consistent with a heterogeneous rupture process where failure is controlled largely by the size and location of high-strength asperity regions.
\end{abstract}

\section{INTRODUCTION}

Recordings of earthquake ground motion near the source are very valuable for inferring the distribution of slip as a function of position on the fault plane (e.g., Olson and Apsel, 1982; Hartzell and Heaton, 1983; Archuleta, 1984). However, most earthquakes do not occur in regions covered by arrays of strong-motion instruments that record the near-field disturbances. In their study of the rupture history of the Imperial Valley earthquake from the inversion of near-source ground motions, Hartzell and Heaton (1983) also computed a dislocation model using short- and long-period Worldwide Standardized Seismograph Network (WWSSN) body waves recorded at teleseismic distances $\left(30^{\circ}\right.$ to $\left.90^{\circ}\right)$. They found that the teleseismic model, although lacking in detail, showed the same general pattern of slip on the fault plane as the strong-motion result (Hartzell and Heaton, 1983). In addition, they observed that the position of the maximum dislocation in the teleseismic model was significantly less sensitive to changes in the assumed rupture velocity than for the model obtained from the strong-motion data. Changes in rupture velocity of 10 per cent of the shear-wave velocity resulted in differences of, at most, $2 \mathrm{~km}$ in the position of the peak slip determined from the WWSSN data for the Imperial Valley earthquake. These findings suggest that the analysis of teleseismically recorded earthquake waveforms is useful for in- 
TABLE 1

\begin{tabular}{|c|c|c|c|c|c|c|}
\hline \multirow{2}{*}{ Event } & \multirow{2}{*}{ Date } & \multirow{2}{*}{$\begin{array}{l}\text { Hr:Min :Sec } \\
\text { (UTC) }\end{array}$} & \multicolumn{2}{|c|}{ Epicenter } & \multirow{2}{*}{$\begin{array}{c}\text { Magnitude } \\
\left(M_{S}\right)\end{array}$} & \multirow{2}{*}{$\begin{array}{c}\text { Depth } \\
(\mathrm{km})\end{array}$} \\
\hline & & & ${ }^{\circ} \mathrm{N}$ & ${ }^{\circ} \mathrm{W}$ & & \\
\hline North Palm Springs & 8 July 1986 & $9: 20: 44.0$ & 34.00 & 116.61 & 6.0 & $11.3^{*}$ \\
\hline Borah Peak & 28 October 1983 & $14: 06: 06.6$ & 44.06 & 113.86 & 7.3 & $16.0 \dagger$ \\
\hline Michoacan & 19 September 1985 & $13: 17: 48.1$ & 18.27 & 102.31 & 8.1 & $17.0 \div$ \\
\hline
\end{tabular}

* Jones et al. (1986).

$\uparrow$ Doser and Smith (1985).

$\doteqdot$ Eissler et al. (1986).

ferring the gross features of fault slip when strong-motion records are not available (Hartzell and Heaton, 1983). Hartzell and Heaton (1986) also modeled teleseismic short-period $P$ waveforms recorded at stations of the Global Digital Seismograph Network (GDSN) for the Morgan Hill earthquake. They found strong support for a two-source model implied by the strong-motion data. The results of Hartzell and Heaton $(1983,1986)$ imply that, due to the accessibility of the high-quality digital signals, reasonably accurate models of earthquake rupture can be readily obtained using GDSN teleseismic records.

The purpose of this study is to compute the rupture history of three recent earthquakes that span a large magnitude range using the GDSN teleseismic $P$ waveforms. The events are: the 8 July $1986\left(M_{S}=6.0\right)$ North Palm Springs, California, earthquake; the 28 October $1983\left(M_{S}=7.3\right)$ Borah Peak, Idaho, earthquake; and the 19 September $1985\left(M_{S}=8.1\right)$ Michoacan, Mexico, earthquake. Hypocentral parameters for these three earthquakes are listed in Table 1. Except for the depths, the parameters of Table 1 are those reported by the National Earthquake Information Center.

The slip models that we obtain for the North Palm Springs and Borah Peak earthquakes using $P$ waveforms alone compare well with patterns of fault slip determined by other workers from an analysis of near-source strong-motion or geodetic data. For the Michoacan earthquake, our dislocation model is similar to the distribution of moment release obtained by Houston (1987) using the Kikuchi and Fukao (1985) method of waveform inversion. This method, which is modified from Kikuchi and Kanamori (1982), uses an iterative deconvolution scheme where the fault plane is represented by a uniform grid of point sources. The synthetic seismogram for an initial source is first subtracted from the observations. The strength, location, and initiation time of this source is determined by cross-correlation of the synthetic and data records. This process is continued for several iterations until an acceptable fit, measured in a least-squares sense, is obtained to the data. The method of Hartzell and Heaton $(1983,1986)$, which we use in this study, has the advantage that it is fully linear, although the highfrequency resolution and the range in allowable model parameters may be limited by computational practicalities. This is because the maximum frequency that can be modeled depends on the number and dimensions of the individual subfaults chosen to represent the fault plane.

\section{INVERSION METHOD}

We use the point-by-point inversion method of Hartzell and Heaton (1983, 1986) to obtain three-dimensional dislocation models for the North Palm Springs, Borah Peak, and Michoacan earthquakes. This technique is fully described by 
Hartzell and Heaton (1983) and will only be briefly discussed here. Initially, a rectangular plane with fixed strike, dip, and dimensions is chosen to represent the fault surface. The position of the hypocenter on the fault is also fixed. The fault plane is then embedded at the appropriate depth in the crustal structure of the earthquake source region. Table 2 provides a summary of the crustal velocity models used in this study. Except for the upper layer in the North Palm Springs model, shear-wave velocities $\left(V_{S}\right)$ were computed from the $P$-wave velocity $\left(V_{P}\right)$ by assuming Poisson materials: $V_{P}=\sqrt{3} V_{S}$. For North Palm Springs, the uppermost layer was assumed to be slightly less rigid to better approximate the local geologic conditions. Corresponding densities were taken from the empirical curve of Grant and West $(1965$, p. 200) that relates density to $P$-wave velocity.

The fault is then subdivided into $N$ subfaults of equal size. The value of $N$ depends on the frequency content of the data to be inverted and on the dimensions of the fault plane. An appropriate number of point sources is uniformly distrib. uted over each subfault so that failure of the subfault appears smooth for a rupture propagating at a constant velocity away from the hypocenter. Because rupture-velocity values generally remain within the range of 0.8 to 0.9 of the shearwave velocity for most earthquakes, we take the rupture velocity to be either 80 or 85 per cent of the local shear-wave speed. However, for the Michoacan earthquake, a factor of 0.8 produced a solution where major portions of slip were forced to reside at the far extremities of the fault plane and, instead, we chose a factor of 0.7 to obtain a more realistic velocity value. Assuming uniform displacements for both strike-slip and dip-slip components, we generate synthetic, vertical $P$ waveforms for each subfault at all stations for which data are available.

The synthetic ground motions are calculated using the generalized ray summation technique described by Heaton (1982). In this study, we include all rays with up to two internal reflections in the layered structure (Table 2). We also include $P$ to $S$ and $S$ to $P$ conversions for direct rays and for upgoing rays reflected at the free surface. Thus, $p P$ and $s P$ contributions to the teleseismic waveforms

TABLE 2

Near-Source Crustal Velocity Models Used in this Study

\begin{tabular}{|c|c|c|c|c|}
\hline Region & $\begin{array}{l}\text { Top Depth } \\
(\mathrm{km})\end{array}$ & $\begin{array}{c}V_{P} \\
(\mathrm{~km} / \mathrm{sec})\end{array}$ & $\begin{array}{c}V_{S} \\
(\mathrm{~km} / \mathrm{sec})\end{array}$ & $\begin{array}{c}\text { Density } \\
\left(\mathrm{gm} / \mathrm{cm}^{3}\right)\end{array}$ \\
\hline \multirow[t]{4}{*}{ North Palm Springs, California* } & 0.0 & 3.40 & 1.70 & 2.28 \\
\hline & 1.6 & 5.27 & 3.04 & 2.58 \\
\hline & 5.5 & 6.56 & 3.79 & 2.80 \\
\hline & 37.0 & 7.80 & 4.50 & 2.95 \\
\hline \multirow[t]{4}{*}{ Borah Peak, Idaho ${ }^{\dagger}$} & 0.0 & 4.75 & 2.74 & 2.50 \\
\hline & 2.0 & 5.98 & 3.45 & 2.70 \\
\hline & 18.0 & 6.80 & 3.93 & 2.83 \\
\hline & 40.0 & 8.00 & 4.62 & 3.00 \\
\hline \multirow[t]{4}{*}{ Michoacan Coast, Mexico $\neq$} & 0.0 & 5.80 & 3.35 & 2.68 \\
\hline & 6.0 & 6.40 & 3.69 & 2.78 \\
\hline & 25.0 & 7.00 & 4.04 & 2.85 \\
\hline & 35.0 & 8.00 & 4.62 & 3.00 \\
\hline
\end{tabular}

* Hadley and Kanamori (1977) and Green (1983).

+ Richins et al. (1987).

‡ Stolte et al. (1986). 
are considered in the inversion. Attenuation is incorporated using a constant $t^{*}$ (travel time/average seismic quality factor $Q$ along ray) of 0.7 for both shortperiod and long-period synthetics. Der et al. (1982) found $t^{*}$ to vary between 0.3 and 1.0 for $P$ waves in the period range of 1 to $50 \mathrm{sec}$. For a $t^{*}$ of 0.5 , the amplitudes at $0.5 \mathrm{~Hz}$, which is the approximate frequency limit of the data analyzed in this study, differ by a factor of 1.3. Using a lower value for $t^{*}$ would produce synthetics that have a greater high-frequency content and dislocation models that have lower peak values of slip. However, the moment is constrained by the long-period data, which is less sensitive to the value of $t^{*}$.

The synthetic waveforms and observed vertical seismograms describe an overdetermined system of linear equations of the form $A x=b$, where $A$ is an $m$ $x n$ matrix of synthetics, and $x$ is a vector of length $n$ of the subfault strike-slip and dip-slip dislocation weights required to reproduce the observed data vector $b$ (length $m$ ). We solve for $x$ using a Householder least-squares inversion scheme (Lawson and Hanson, 1974) that invokes a positivity constraint on the solution. For matrices with large dimensions, like for the Michoacan earthquake, we use a sequential Householder technique where the matrix $A$ is sequentially uppertriangularized to reduce the matrix to a more manageable size. The nonnegative constraint is imposed not only because it is physically desirable, but also because negative slips lead to destructive interference between subfaults, producing unstable solutions (Hartzell and Heaton, 1983). Stability is additionally imposed by requiring that the solution have a smoothly varying spatial distribution. This smoothing constraint is applied by including a set of linear constraints of the form $F x=d$ such that

$$
\left[\frac{A}{\lambda F}\right] x=\left[\frac{b}{\lambda d}\right]
$$

where $\lambda$ is a scalar weighting factor. By letting the set of equations $F x=d$ take a form such that the difference between adjacent dislocation weights $x$ is zero, the solution is constrained to vary smoothly across the fault. In this context, the weighting factor $\lambda$ selects the amount of smoothing constraints to impose on the solution. The actual value of this smoothing factor depends on the nature of the particular problem. Our goal was to apply as much smoothing as we could without significantly perturbing the overall fit to the observed waveforms. This approach provides a way of arriving at the least complicated solution that still satisfies the observed data.

In the aforementioned linear formulation of the problem, a constant rupture velocity is assumed. However, flexibility in rupture time of individual subfaults can be easily incorporated by subdividing the source-time function into time slices and solving for the contribution within each time window (Hartzell and Heaton, 1983). In this way, each subfault is allowed to rupture several times to construct a possibly complicated source-time function. Other authors have solved this problem by abandoning linearity and solving for rupture time (e.g., Kikuchi and Kanamori, 1982; Yoshida, 1986). Our parameterization, although linear, can greatly increase the number of unknowns that must be inverted for. In this paper, we have assumed a constant source-time function (i.e., each subfault is allowed to slip once). A triangular source-time function with fixed duration is used for all three earthquakes. A rise time of $0.6 \mathrm{sec}$ is used for both the North Palm 
Springs and Borah Peak earthquakes, and a 2-sec rise time is used for the Michaocan, Mexico, earthquake.

As pointed out by Hartzell and Heaton (1983), correct timing of the waveforms is crucial in the inversion of teleseismic data. The accurate determination of the slip pattern across a fault requires a precise knowledge of the $P$-wave arrival times at the teleseismic stations. Small errors in timing can result in large differences in the location of moment release on the fault plane. For example, for a rupture velocity of $3.0 \mathrm{~km} / \mathrm{sec}$, an error of $1 \mathrm{sec}$ in timing could result in mislocation errors as large as $3 \mathrm{~km}$. To minimize this problem, waveform start times are chosen from the available short-period records. Generally, a preliminary inversion run is conducted by weighting down stations lacking any short-period data. In subsequent runs, down-weighting is relaxed for these stations, and their record start times are adjusted to correspond to the times indicated by the preliminary run.

The length of the record is also important for inferring the temporal and spatial character of the source process. We must be sure to accommodate possible slip contributions along the entire length and width of the fault model without including unmodeled reverberations or complex body-wave energy interactions that may result from a complicated near-receiver structure. Record lengths thus depend on the model parameters (i.e., dimensions and rupture velocity) and are dictated by the length of the synthetic waveform for the subfault farthest from the hypocenter plus the amount of time required for rupture to propagate to that distance.

\section{The July 1986 North Palm Springs, California, Earthquake}

The fault dimensions used in the inversion of the North Palm Springs data are shown in Figure 1. The size of the fault was chosen to generously encompass the distribution of aftershock hypocenters computed by Jones et al. (1986). The fault plane is subdivided into 88 subfaults with dimensions of $2.0 \mathrm{~km} \times 1.9 \mathrm{~km}$. The strike $\left(287^{\circ}\right)$ and $\operatorname{dip}\left(46^{\circ}\right)$ were taken from the point-source fault parameters initially computed by Pacheco and Nábělek (1986) for the North Palm Springs earthquake using long-period $P$ and $S H$ waveforms recorded at worldwide stations. Recently, Pacheco and Nábělek (1988) have revised their mechanism solution, but the strike and dip angles remain within $5^{\circ}$ of the initial values. The fault strike coincides well with the general trend of the aftershock distribution observed by Jones et al. (1986). Also, the aftershock zone dips to the northeast at an angle very similar to the fault dip estimated by Pacheco and Nábělek (1986, 1988). This geometry corresponds to a dipping rectangular fault spanning a depth range of 4 to $15 \mathrm{~km}$ below the surface. The large dot in Figure 1 indicates the position of the hypocenter on the fault, assuming a hypocentral depth of $11 \mathrm{~km}$. Rupture over the fault is assumed to propagate radially from the hypocenter at a velocity of $3.0 \mathrm{~km} / \mathrm{sec}$. This value is equal to 80 per cent of the shear-wave velocity of layer 3 in the near-source structure of Table 2.

We used a total of 19 GDSN $P$ waveforms in the inversion for the slip distribution of the North Palm Springs earthquake: 11 long-period, 2 intermediateperiod, and 6 short-period records. The long-period record lengths were fixed at $60 \mathrm{sec}$, and 12.5-sec windows were used for the short-period and intermediateperiod data. Initially, we inverted only the long-period GDSN $P$ waveforms; in a subsequent run, we included the short- and intermediate-period data. The results are summarized in Figure 2. In the figure, dislocation on the fault is contoured at $20-\mathrm{cm}$ intervals. Components of right-lateral strike-slip motion (top) 
PALM SPRINGS

\begin{tabular}{|c|c|c|c|c|c|c|c|c|c|c|}
\hline 1 & 9 & & & & & & & & & 81 \\
\hline 2 & $\vdots$ & & & & & & & & & 82 \\
\hline 3 & & & & & & & & & & 83 \\
\hline 4 & & & & & & & & & & 84 \\
\hline 5 & & & & & & & & & & 85 \\
\hline 6 & & & & & & & & & & 86 \\
\hline 7 & & & & & & & & & $\vdots$ & 87 \\
\hline 8 & & & & & & & & & 80 & 88 \\
\hline 0
\end{tabular}

Fig. 1. Fault dimensions adopted for the North Palm Springs earthquake, as viewed from above in a direction perpendicular to the fault surface. The large dot indicates the location of the hypocenter. The top of the fault is at a depth of $4 \mathrm{~km}$ below the surface.

and reverse dip-slip motion (center) are shown separately from the resultant slip (bottom). The dislocation model obtained using only the long-period data is on the left portion of the figure. These results imply that the long-period waveforms provide few constraints on the distribution of slip. However, the long-period data actually constrain the overall dimensions of the rupture and define the seismic moment of the earthquake. When the short-period data are included in the inversion, the resulting dislocation model (right half of Figure 2) contains variations in the slip pattern not previously observed with the long-period data alone.

The fits between the observed data (top trace) and synthetic waveforms (bottom trace) for each of the GDSN stations used to compute our final dislocation model (Figure 2, right side) are shown in Figure 3. The final model gives a seismic moment $\left(M_{0}\right)$ of $1.7 \times 10^{25}$ dyne-cm. This value is computed by using the relation

$$
M_{0}=\sum \mu_{i} A s_{i}
$$

where $s_{i}$ is the vector sum of the slip components for the $i$ th subfault, and $\mu_{i}$ is the corresponding shear rigidity. $A$ is the subfault area. Pacheco and Nabělek (1988) computed a moment of $9.7 \times 10^{24}$ dyne-cm using primarily WWSSN longperiod teleseismic data. Part of the discrepancy may be due to differences in the assumed crustal structure. However, we consider the two moment values to be similar, given the uncertainties in estimating the seismic moment.

The computed dislocation model of Figure 2 indicates that the North Palm Springs earthquake resulted from the rupture of two localized areas: a $6 \mathrm{~km} \times$ $4 \mathrm{~km}$ main source near the hypocenter and a $3 \mathrm{~km} \times 5 \mathrm{~km}$ zone farther updip. Rupture of the shallow zone is almost entirely right-lateral strike-slip, while the main dislocation is also accompanied by a thrust component of dip-slip motion. The peak values of the dip-slip and strike-slip components for the main source suggest an effective rake angle of about $150^{\circ}$. The rake angle of $147^{\circ}$ computed by Pacheco and Nábělek (1988) assuming a point source provides strong support for our slip-distribution model. Additional support is provided by results obtained from the inversion of the strong-motion data recorded for the North Palm Springs earthquake. Preliminary results suggest a slip pattern similar to our model, although the actual dimensions of the dominant source may be somewhat larger (Hartzell et al., 1988). 


\section{PALM SPRINGS}

LONG PERIOD P-WAVES
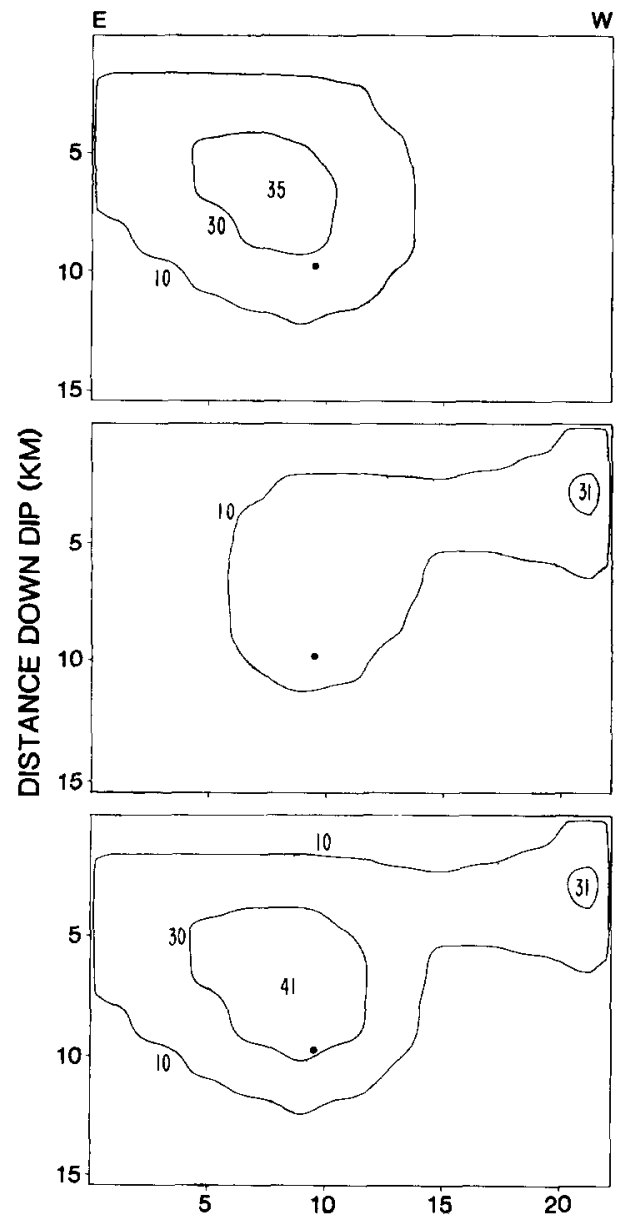

DISTANCE ALONG STRIKE (KM)
LONG AND SHORT PERIOD P-WAVES
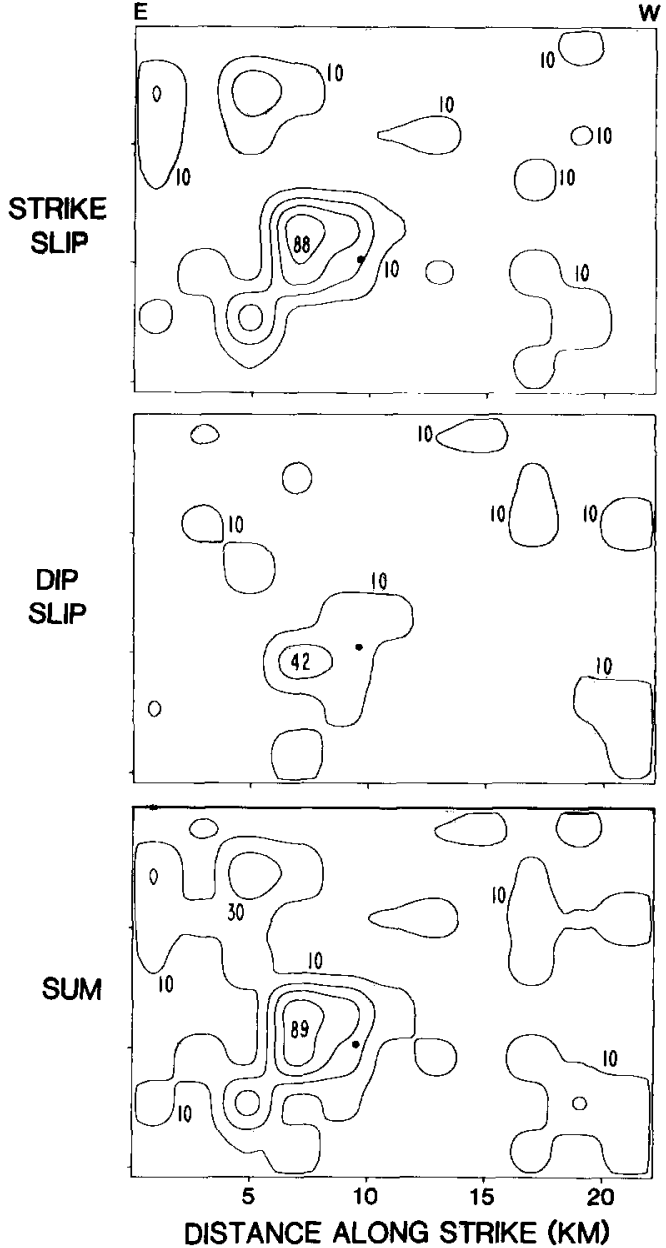

FIG. 2. Results of the linear inversion for the North Palm Springs earthquake. Strike-slip (top) and dip-slip (center) dislocations, and their vector sum (bottom), are contoured at $20-\mathrm{cm}$ intervals beginning at the 10-cm level. Frames on the left side of the figure denote the dislocation model obtained using only the long-period GDSN data. The dislocation model on the right is the solution obtained when short-period data are included in the inversion.

We have computed the stress drop $\Delta \sigma$ across the two slip zones using the relation

$$
\Delta \sigma=\frac{7 \pi}{16}\left(\frac{\bar{S}}{r}\right)
$$

for a circular fault of radius $r$ (Eshelby, 1957). $\bar{S}$ is the average slip estimated

FIG. 3. (A) Comparison of observed (upper trace) and synthetic (lower trace) GDSN long-period $P$ waveforms for the North Palm Springs dislocation model. Peak amplitudes are given in hundreds of digital counts. Amplitudes of the synthetics are for a moment of $1.7 \times 10^{25}$ dyne-cm. The focal sphere shows the distribution of GDSN stations and the nodal planes for the point-source mechanism computed by Pacheco and Nábèlek (1986). The fault plane is indicated by a solid line. (B) Comparison of observed (upper trace) and synthetic (lower trace) GDSN short- and intermediate-period $P$ waveforms for the North Palm Springs dislocation model. Amplitude properties and focal-sphere information are the same as in $(A)$. 

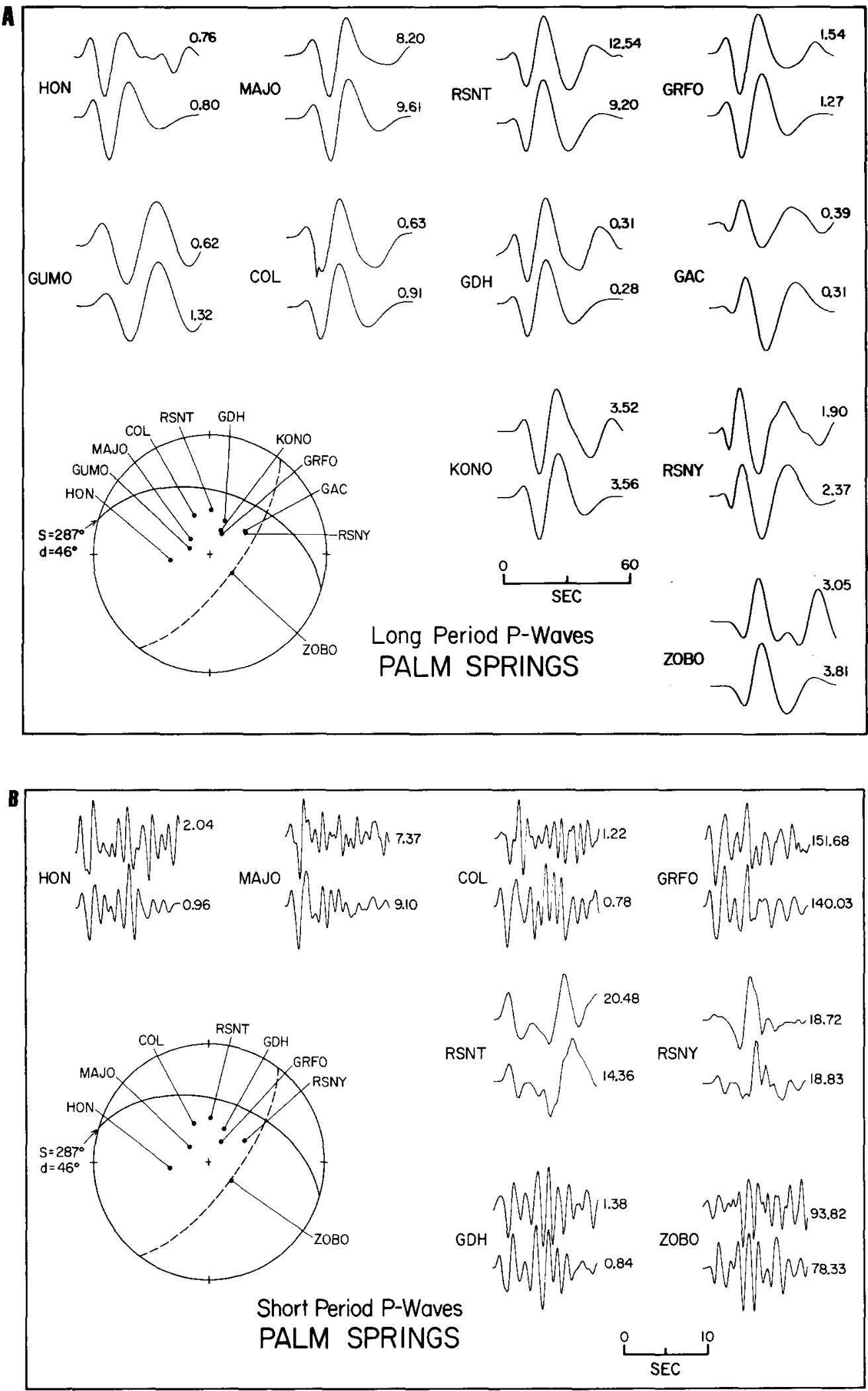
over the circular area. Stress drops are 101 and 92 bars for the main and shallow source zones, respectively.

\section{The October 1983 Borah Peak, Idaho, Earthquake}

A model of slip distribution for the Borah Peak earthquake has been previously obtained by Ward and Barrientos (1986) from the inversion of geodetic observations. Ward and Barrientos (1986) inverted the difference between leveling lines surveyed in the area in $1933 / 1948$ and in July 1984 to obtain a model of fault slip. We have adopted the same fault strike $\left(152^{\circ}\right)$ and $\operatorname{dip}\left(49^{\circ}\right)$ as $W$ ard and Barrientos (1986) in our analysis, although we place the fault at a depth of $1 \mathrm{~km}$ below the surface. As mentioned before, our parameterization requires subdivision into subfaults. We use a total of 128 subfaults with dimensions of $3.25 \mathrm{~km} \times 3.3 \mathrm{~km}$ (see Figure 4) to obtain fault dimensions similar to those of Ward and Barrientos (1986). This is desirable because we wish to compare our results with their slip-distribution model. Such a comparison helps assess the ability of the GDSN teleseismic data to yield realistic results and, also, provides an opportunity to examine differences in the coseismic and postseismic slip on the fault surface. In our inversion, we use a rupture velocity of $2.9 \mathrm{~km} / \mathrm{sec}$, which corresponds to 85 per cent of the $S$-wave velocity of the second layer in the crustal structure of Table 2.

For the Borah Peak earthquake, we used a total of 23 GDSN records: 14 longperiod and 9 short-period records. Record lengths were fixed at $60 \mathrm{sec}$ for the long-period waveforms and $25 \mathrm{sec}$ for the short-period data. As with the North Palm Springs earthquake, we inverted the long-period data first and then included the short-period waveforms with the long-period data in a subsequent run. We had difficulty inverting both sets of data simultaneously, suggesting that the long-period and short-period waveforms recorded for the Borah Peak earthquake contain incompatible information. In particular, the higher frequencies in the short-period records were difficult to fit. This prompted us to low-pass filter the short-period data and synthetics at $0.5 \mathrm{~Hz}$ using a Butterworth filter prior to the inversion. The resulting dislocation models are shown in Figure 5 using the same format as for the results of the North Palm Springs earthquake. Again, the solution depends on constraints imposed by both long- and short-period components;

\section{BORAH PEAK}

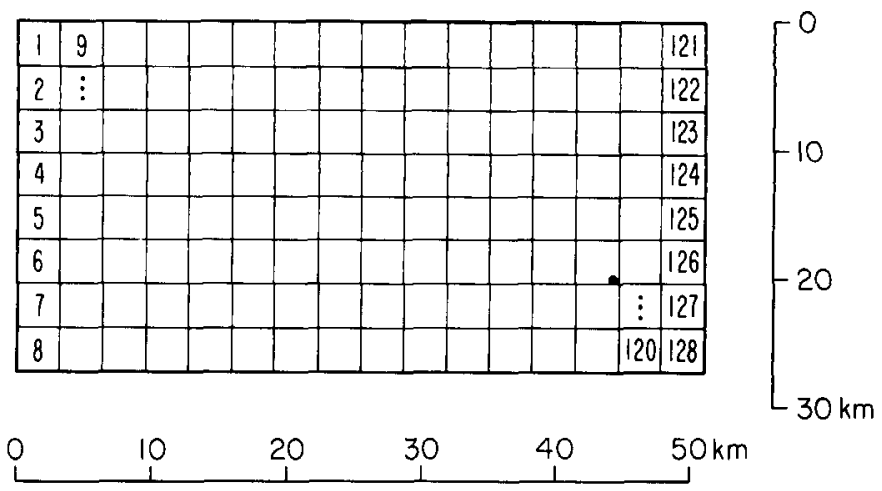

FIG. 4. Fault dimensions adopted for the Borah Peak earthquake, as viewed from above in a direction perpendicular to the fault surface. The large dot indicates the location of the hypocenter. The top of the fault is at a depth of $1 \mathrm{~km}$ below the surface. 
BORAH PEAK
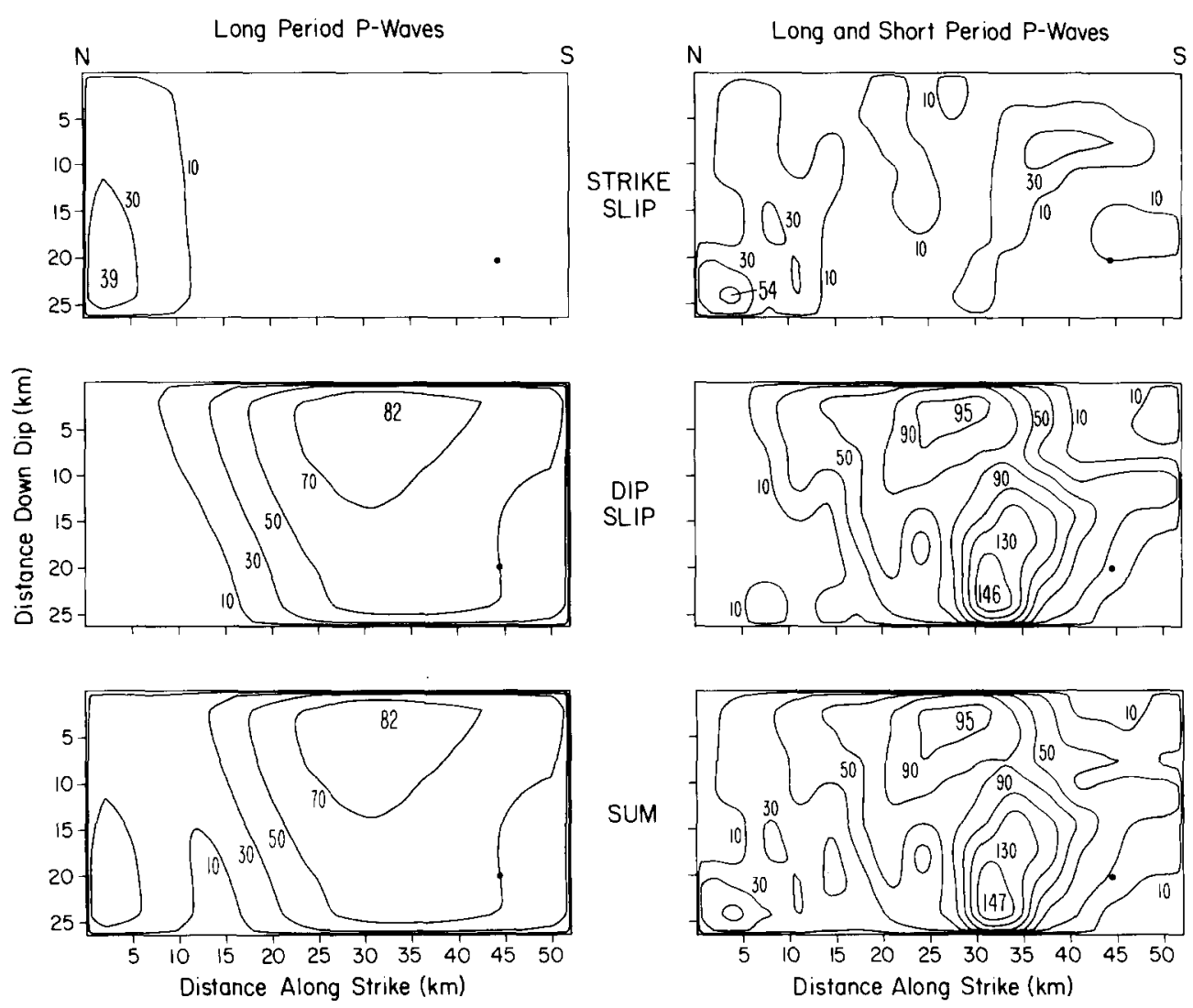

FIG. 5. Results of the linear inversion for the Borah Peak earthquake. Strike-slip (top) and dipslip (center) dislocations, and their vector sum (bottom), are contoured at $20-\mathrm{cm}$ intervals beginning at the 10-cm level. Frames on the left side of the figure denote the dislocation model obtained using only the long-period GDSN data. The dislocation model on the right is the solution obtained when short-period GDSN data are low-pass-filtered at $0.5 \mathrm{~Hz}$ and included in the inversion.

the long-period waveforms outline the general rupture dimensions, and the lowpass filtered short-period data provide additional information on the variation of coseismic displacement.

Our inability to invert the higher frequencies contained in the short-period records could be due to a source effect related to the size of the earthquake. That is, due to the larger size of the Borah Peak earthquake, a complex rupture may have taken place with variable rupture velocity and/or multiple sequences of starting and stopping. Because such variables are not included in our parameterization, any high-frequency contributions from widely separated regions at nondeterministic times would be difficult to model. Another possibility is that details of the rupture occurring at scales smaller than our subfault size contribute significantly to the radiation of high-frequency seismic waves.

The difficulty may also result from propagation effects not accounted for in the inversion. For example, the near-source and/or near-receiver crustal models that we use may not be accurate representations of the actual geologic structure. Our near-source crustal model (Table 2) is essentially the velocity model of Richins et al. (1987), which is based on refraction profiles in the immediate vicinity of the Borah Peak epicenter. Therefore, we consider our crustal model to depict 
accurately the geologic structure in the earthquake source area. However, receiver sites are represented by a half-space, and strong body-wave interaction near the recording stations would not be included in the inversion. Also, strong scattering near the source or receiver due to small-scale heterogeneities might prevent a proper modeling of the high-frequency data. Related to this are highfrequency attenuation effects that may not be corrected for with our constant $t^{*}$ operator.

In Figure 6, the synthetic waveforms (bottom trace) from the preferred dislocation model are compared with the observed data (top trace). The synthetics fit the observations remarkably well, even for most of the low-pass filtered shortperiod signals. However, the tail end of some of the short-period records (e.g., COL, HON, and RSNY) are not particularly well fit (Figure 6B). Considering that the majority of the slip originates within an area much smaller than the fault dimensions initially assumed for the earthquake, the 25-sec record length chosen may be too large. At these stations, the last 5 to 6 sec probably contain unmodeled reverberations or other propagation effects not accounted for by our assumed near-source or near-receiver structure. The seismic moment of our preferred model is $2.3 \times 10^{26}$ dyne-cm. Doser and Smith (1985) obtained a similar moment $\left(2.1 \times 10^{26}\right.$ dyne-cm) from a point-source inversion of the teleseismic body waves. Ward and Barrientos (1986) computed a seismic moment of $2.6 \times$ $10^{26}$ dyne-cm from the geodetic data.

Our inversion results for the Borah Peak earthquake suggest that slip during the main shock was mostly normal dip-slip. The localized strike-slip displacement evident in Figure 5 is relatively small and does not contribute significantly to the overall character of the earthquake source. This result is supported by the centroidal moment-tensor mechanism computed by Doser and Smith (1985) using WWSSN and GDSN long- and short-period body waves. They obtain a slip angle of $-72^{\circ}$ (Doser and Smith, 1985). In addition, the shape of our dislocation model is similar to the slip distribution obtained by Ward and Barrientos (1986) from the inversion of the geodetic data, although slip extends deeper in our model. These similarities indicate that our solution provides a constrained representation of the source and is not the result of an unstable minimization of the misfit between observed and synthetic records.

A major difference between our model and that of Ward and Barrientos (1986) is the magnitude of the peak displacements. The geodetic data require a broad source at depth with about $2 \mathrm{~m}$ of displacement and near-surface slip as large as $4 \mathrm{~m}$ in places (see Figure 6 of Ward and Barrientos, 1986). The distribution of normal slip resulting from our inversion (Figure 5, right center) also shows two zones of maximum displacement. A large lobe with a peak displacement of about $1.5 \mathrm{~m}$ is located at depth near the hypocenter. The second lobe is shallower, covers a smaller area, and has a lower peak amplitude (about $1 \mathrm{~m}$ ). This shallow zone, which is within $5 \mathrm{~km}$ of the top edge of the fault, may correspond to the knots of 3- to 4-m slip obtained by Ward and Barrientos (1986) on the shallow portion of the fault. The discrepancy in the peak values is due either to differences in coseismic and postseismic slip near the surface or to the lack of body-wave energy contributions to the teleseismic records that result from cancellation of upgoing and downgoing rays. Although such destructive interference is probably taking place, our peak displacement of $1.0 \mathrm{~m}$ for the shallow source does not seem unreasonable in view of the static displacements observed by Crone et al. (1985) on the surface faults activated during the Borah Peak earthquake. The average 

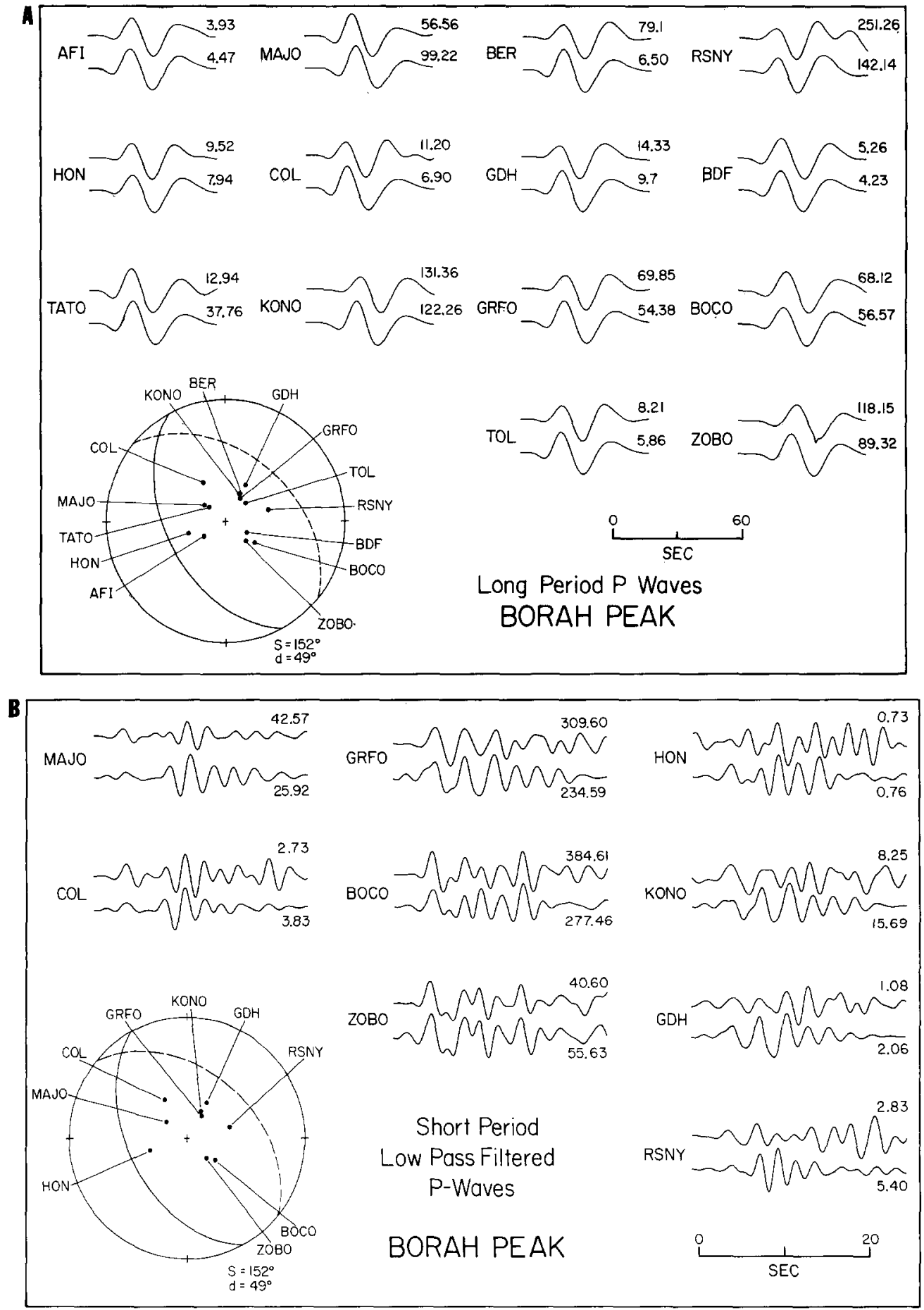

FIG. 6. (A) Comparison of observed (upper trace) and synthetic (lower trace) GDSN long-period $P$ waveforms for the Borah Peak dislocation model. Peak amplitudes are given in hundreds of digital counts. Amplitudes of the synthetics are for a moment of $2.3 \times 10^{26}$ dyne-cm. The focal sphere shows the distribution of GDSN stations and also the fault parameters obtained by Ward and Barrientos (1986) for a fixed-strike orientation of the earthquake fault (solid line). (B) Comparison of observed (upper trace) and synthetic (lower trace) GDSN short-period $P$ waveforms for the Borah Peak dislocation model. Data and synthetics were low-passed-filtered at $0.5 \mathrm{~Hz}$. Amplitude properties and focal-sphere information are the same as in (A). 
throw on these faults along the length of the rupture is about $1.5 \mathrm{~m}$, although the throw at two isolated points was measured at 2.5 and $2.7 \mathrm{~m}$ (see Crone et al., 1985).

We estimate the stress drops for the deep and shallow slip zones at 46 and 48 bars, respectively, using equation (3). The stress drop across the entire rupture area is about 25 bars due to the decreased average slip over the broader region that includes both source zones. This value is in excellent agreement with the average stress drop of 28 bars obtained by Boatwright and Choy (1986) for the Borah Peak earthquake.

\section{The September 1985 Michoacan, Mexico, Earthquake}

Source properties for this earthquake have been previously obtained by several investigators (e.g., Eissler et al., 1986; Ekstrom and Dziewonski, 1986; Houston and Kanamori, 1986; Priestley and Masters, 1986; Riedesel et al., 1986). Most of these studies have concentrated on the derivation of centroidal source parameters. However, Houston (1987) was able to determine the distribution of moment release on the fault surface using the method of Kikuchi and Fukao (1985). In this method, which we briefly described earlier, individual point-source subevents with a common mechanism are mapped onto the assumed earthquake fault. Although the slip angle is fixed in the Kikuchi and Fukao (1985) method, the resulting moment distribution (Houston, 1987) provides a model with which to compare our solution obtained with no restrictions on rake.

We adopt a fault geometry only slightly different than that of Houston (1987). We use a strike of $300^{\circ}$ and a dip of $14^{\circ}$ based on the long-period point-source mechanisms obtained in the previous studies and on the distribution of aftershock hypocenters (e.g., Stolte et al., 1986). Our chosen fault and subfault dimensions (about $10 \mathrm{~km}$ on a side for each subfault) are shown in Figure 7. These fault dimensions yield a depth extent of 6 to $40 \mathrm{~km}$ assuming a hypocentral depth of $17 \mathrm{~km}$ (from Eissler et al., 1986). Houston (1987) used the same hypocentral depth

\section{MICHOACAN, MEXICO}

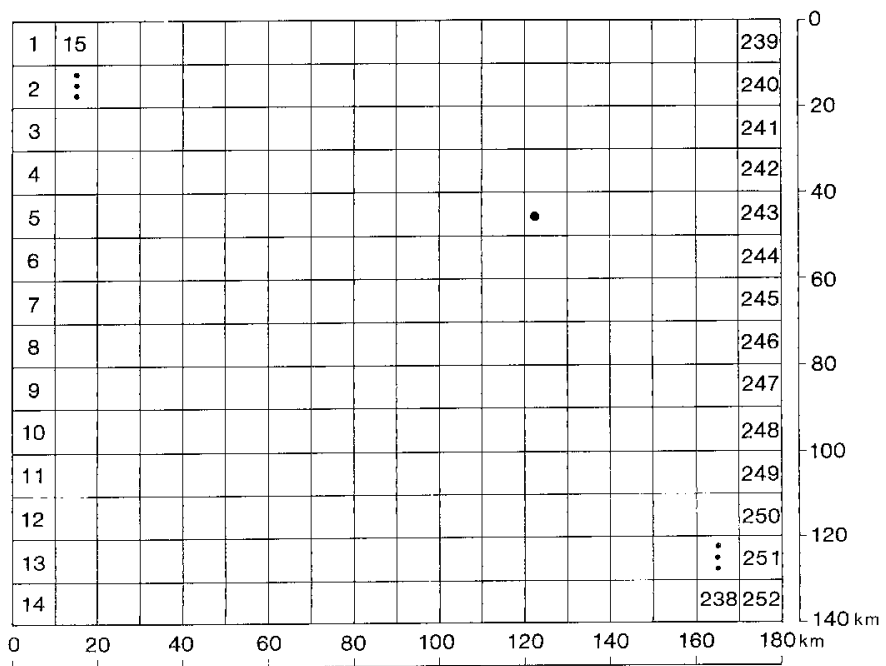

FIG. 7. Fault dimensions adopted for the Michoacan, Mexico, earthquake, as viewed from above in a direction perpendicular to the fault surface. The large dot indicates the location of the hypocenter. The top of the fault is at a depth of $6 \mathrm{~km}$ below the surface. 
but assumed a dip of $10^{\circ}$. Consequently, the corresponding fault model has a width of $100 \mathrm{~km}$ and covers a depth range of about 12 to $30 \mathrm{~km}$. Initially, we assumed a constant rupture velocity equal to 80 per cent of the shear-wave velocity of the second layer in the velocity structure of Table 2. However, upon inversion, this velocity did not accommodate all of the dislocation within our fault dimensions, suggesting that the value was too large. Therefore, we reinverted the data using a rupture velocity equal to 70 per cent of the shear-wave velocity. This velocity $(2.6 \mathrm{~km} / \mathrm{sec})$ is similar to the $2.7 \mathrm{~km} / \mathrm{sec}$ value estimated by Ekstrom and Dziewonski (1986), assuming a unilateral rupture to the southeast.

Although most SRO and ASRO instruments were overdriven during the Miclivacan earthquake, the digital WWSSN stations of the GDSN provided excellent intermediate-period and short-period data. In view of the difficulties associated with the modeling of short-period waveforms and the relatively large size of our subfaults, we excluded the short-period records from the inversion. We inverted 10 intermediate-period waveforms and the 3 long-period records that remained unclipped. We used record lengths of $80 \mathrm{sec}$ for the long-period data and $60 \mathrm{sec}$ for the intermediate-period waveforms.

Initially, we attempted to use the short-period $P$-wave arrivals to select the start times of the waveforms chosen for inversion. However, preliminary runs indicated a discrepancy in the timing between observed and synthetic waveforms. Upon closer inspection, we found that many of the short-period records had a low-amplitude precursor arriving between 5 to $6 \mathrm{sec}$ prior to the main $P$-wave pulse. This suggests that the earthquake may have begun as a very small disturbance near the hypocenter. Because we use a constant rupture velocity, with no allowance for multiple starting and stopping of the rupture, the inversion cannot model this small disturbance. Therefore, we chose start times from the intermediate-period records themselves.

The results of the inversion are shown in Figure 8. The displacement is primarily reverse dip-slip with little strike-slip motion. A similar result is indicated by the point-source focal mechanisms computed in the previous studies (Eissler et al., 1986; Ekstrom and Dziewonski, 1986; Priestley and Masters, 1986; Riedesel et al., 1986). Slip angles obtained in these studies vary between $72^{\circ}$ and $107^{\circ}$.

Several large, independent sources are present in the dislocation model. The largest source, marked $\mathrm{A}$ in Figure 8 , is near the hypocenter and covers an area about $80 \mathrm{~km} \times 50 \mathrm{~km}$. This source consists of two distinct subregions with different peak displacements: 3.7 and $5.7 \mathrm{~m}$. However, this subdivision may be accentuated by our parameterization, which requires the continuous propagation of rupture from the hypocenter. We estimate the stress drop across area $A$ to be 22 bars, although the individual subregions would have greater local stress drops.

Three additional sources are evident in the dislocation model shown in Figure 8. One of these, zone $B$, is a relatively small, circular zone with a maximum slip of $2.9 \mathrm{~m}$. This slip zone is about $50 \mathrm{~km}$ away from the hypocenter and is almost adjacent to another large, irregular source area (zone $\mathrm{C}$ ). This irregular zone has a peak slip of $4.1 \mathrm{~m}$. Another source zone, marked D in Figure 8, is about $75 \mathrm{~km}$ south of the hypocenter. Source D, which has a peak slip of $5.4 \mathrm{~m}$, also contains more than $2 \mathrm{~m}$ of strike-slip displacement near the top edge of the fault. All three sources yield stress drops of about 30 bars.

At first, we were somewhat surprised by the size and position of source D on the shallow portion of the fault plane. Our attemps to remove the source by 


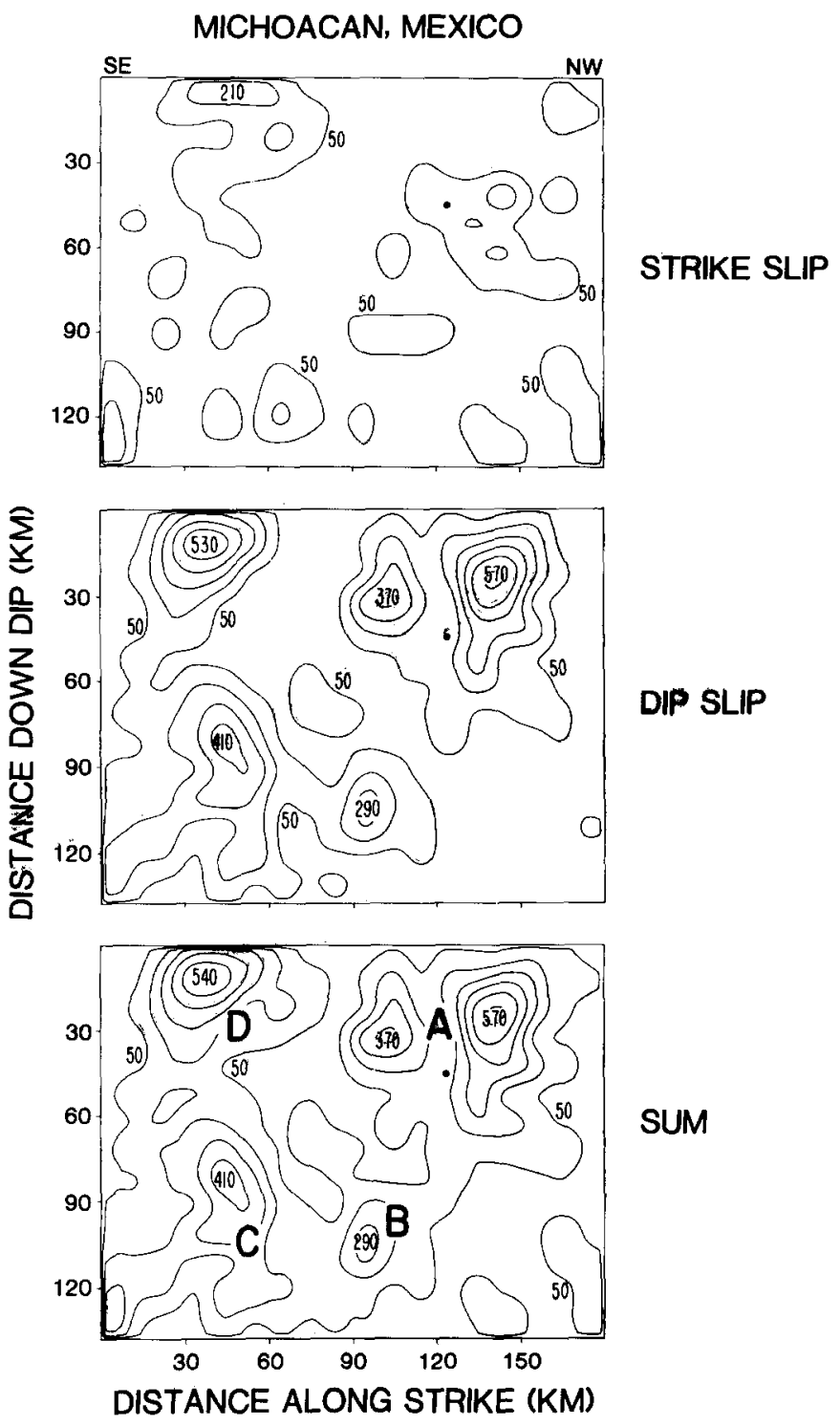

FIG. 8. Results of the linear inversion for the Michoacan, Mexico, earthquake. Strike-slip (top) and dip-slip (center) dislocations, and their vector sum (bottom), are contoured at 100-cm intervals beginning at the 50-cm level. Four major source areas (labeled A, B, C, and D in the lower frame) are evident in the dislocation model.

increasing the smoothing stabilization constraint, however, resulted in a gross inability to fit the latter portion of the teleseismic records. This result suggests that the shallow seismic source is real, at least for frequencies within the passband recorded in the digital intermediate-period waveforms. Houston (1987) also obtained a moment source at a similar position on the fault by inverting simulated long-period WWSSN records. Long-period WWSSN analog records contain frequencies similar to those in the passband of the digital WWSSN intermediateperiod instruments.

In Figure 9, we compare the synthetic waveforms (bottom trace) that we computed for our final dislocation model with the teleseismic GDSN records (top 


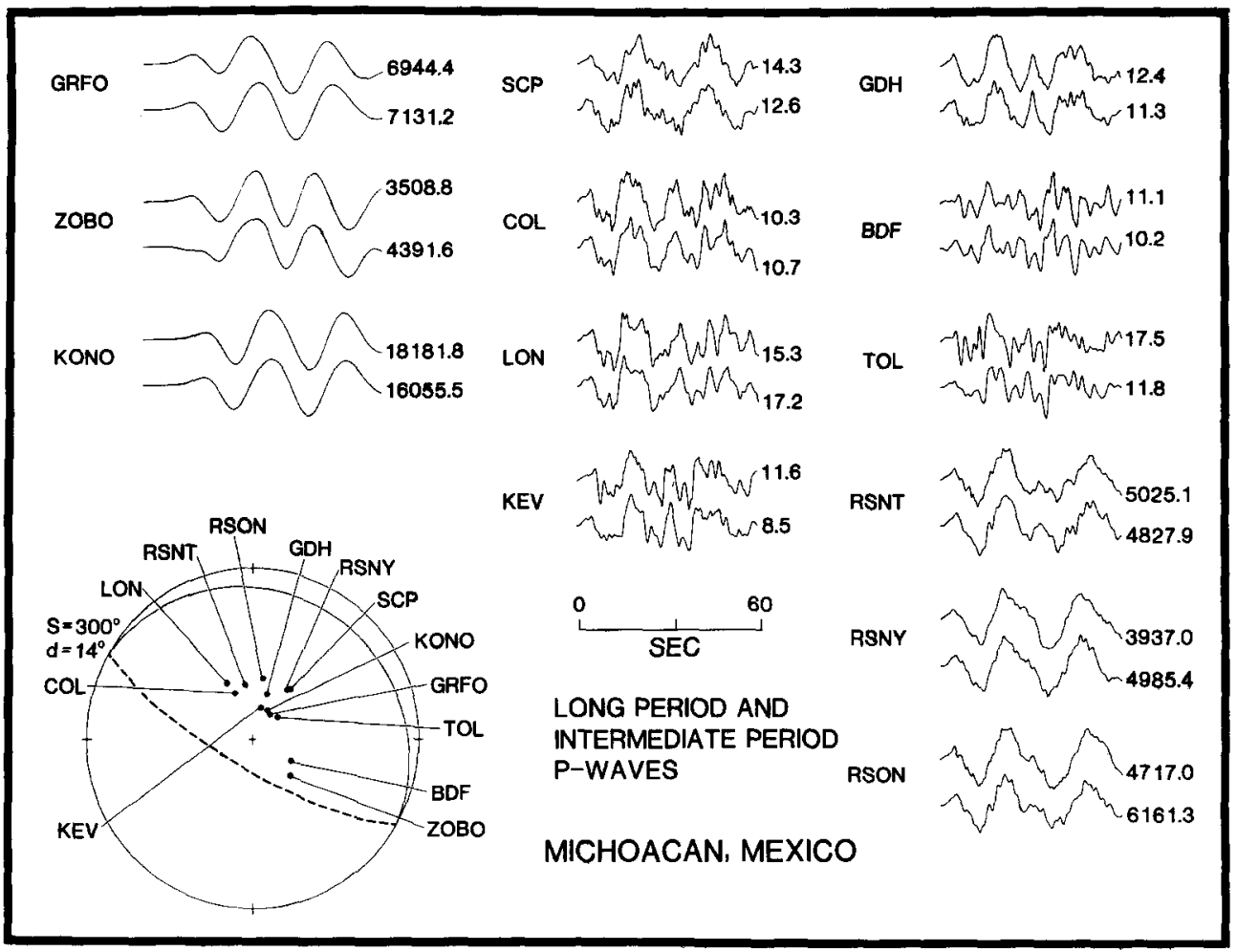

FIG. 9. Comparison of observed GDSN data (upper trace) and synthetic long- and intermediateperiod $P$ waveforms (lower trace) for the dislocation model obtained for the Michoacan, Mexico, earthquake. Peak amplitudes are given in hundreds of digital counts. Amplitudes of the synthetics are for a moment of $1.4 \times 10^{28} \mathrm{dyne}-\mathrm{cm}$. The station distribution is shown on the focal sphere. The dashed line denotes the auxiliary nodal plane that would result for a $90^{\circ}$ rake on the fault (solid line).

trace). The synthetic waveforms, which are computed for a preferred moment of $1.4 \times 10^{28}$ dyne-cm $\left(M_{w}=8.06\right)$, approximate the observed data very well. Our moment estimate is in agreement with the values estimated in other studies. These values vary between 1.0 and $1.7 \times 10^{28}$ dyne-cm (e.g., Eissler et al., 1986). Given the distribution of stations shown in Figure 9, we do not expect the teleseismic data to be highly sensitive to source mislocation in the downdip direction. Therefore, we cannot rule out the possibility that zone $\mathrm{D}$ is actually deeper than indicated by our final solution. Also, body-wave radiation from both sources $\mathrm{C}$ and $\mathrm{D}$ arrive at similar times at the teleseismic stations. Thus, contributions to the teleseismic records from sources $\mathrm{C}$ and $\mathrm{D}$ probably correspond to the second subevent identified by other investigators from the analysis of long-period teleseismic data (e.g., Priestly and Masters, 1986; Ekstrom and Dziewonski, 1986).

As mentioned earlier, we assumed a rise time of $2 \mathrm{sec}$ for the triangular sourcetime function used to generate the synthetic waveforms for the Michoacan earthquake. Because a 2-sec duration might be too short for the dislocation time at any point on the fault for an earthquake of this size, we also computed synthetic waveforms using a trapezoidal source-time function with a 5-sec duration. We low-pass-filtered both the observations and the synthetics at $0.5 \mathrm{~Hz}$ and conducted a separate inversion. Although the resulting slip distribution was generally similar to our previous model, the peak displacements were significantly higher (8.3 $\mathrm{m}$ for source A), requiring a seismic moment of $2.5 \times 10^{28}$ dyne-cm. The large 
moment, together with the poor fit obtained between synthetic and observed records, indicates that the shorter dislocation duration of $2 \mathrm{sec}$ is more appropriate. We have not attempted to determine the optimum source-time duration that would yield the best solution. In actuality, the dislocation time at any point on the fault may vary as a function of position.

\section{Conclusions AND Discussion}

Our analysis of the GDSN teleseismic waveforms recorded for the North Palm Springs, Borah Peak, and Michoacan earthquakes indicate that these records contain sufficient information to allow the retrieval of source dislocation models for moderate to large (magnitude 6.0 to 8.0 ) earthquakes. In our approach, we fix the geometry of a fault plane containing the earthquake hypocenter and divide the fault into a large number of subfaults. By assuming a constant propagation of rupture from the hypocenter, we compute synthetic waveforms at each station for each subfault for both strike-slip and dip-slip components of displacement. We then invert for the amount of slip required of each component per subfault to reproduce the observed seismograms. These weights are converted to actual displacement and contoured to obtain a model of slip variation on the fault.

The distributions of slip that we obtain are consistent with the hypothesis that earthquake occurrence is due to the rupture of strong asperity regions on fault surfaces. The failure of one such region was mainly responsible for the $M_{S} 6.0$ North Palm Springs earthquake. Failure across the asperity covered a small area $(4 \mathrm{~km} \times 6 \mathrm{~km})$ and was predominantly right-lateral strike-slip. The $M_{S} 7.3$ Borah Peak earthquake resulted from normal faulting across a $25 \mathrm{~km} \times 25 \mathrm{~km}$ area that appears to include two asperity regions: a broad zone at depth and a narrower zone near the surface. During the $M_{S}$ 8.1 Michoacan earthquake, at least three different large asperities distributed along a $180-\mathrm{km}$ segment of the Cocos-North American plate boundary failed within a 60 -sec time period.

Figure 10 is a comparison of the results obtained for the three earthquakes analyzed in this study. This comparison serves to emphasize the wide range in asperity size that exists for different regions and for events of different magnitude. Such a variation in asperity distribution has been previously observed by several investigators (e.g., Lay et al., 1983; Ruff and Kanamori, 1983; Hartzell and Heaton, 1985). Also, the figure points out the potential complexity that can be encountered during progressively larger earthquakes. For example, if a great earthquake (like the Michoacan earthquake) appears to be made up of several distinct slip regions, the area between asperities may contain asperity zones at smaller scales (e.g., of the size observed for the 1986 North Palm Springs earthquake). These smaller asperity zones could slip seismogenically without adding substantially to the overall amplitude of the observed waveforms.

Our inversion results suggest that a wide frequency range is necessary to define the slip pattern. The long-period data of the GDSN constrain the dimensions of the coseismic rupture and the seismic moment of the earthquake. Data at periods shorter than those contained in the long-period records provide additional constraints on the variation of slip within the rupture region. However, we had difficulty inverting wavelengths shorter than about 1 or $2 \mathrm{sec}$. Although this may be a result of the manner in which the subfault geometry is parameterized, it may also be a source effect related to a complex rupture history of starting and stopping for large earthquakes. Alternatively, the difficulty could be due to prop- 


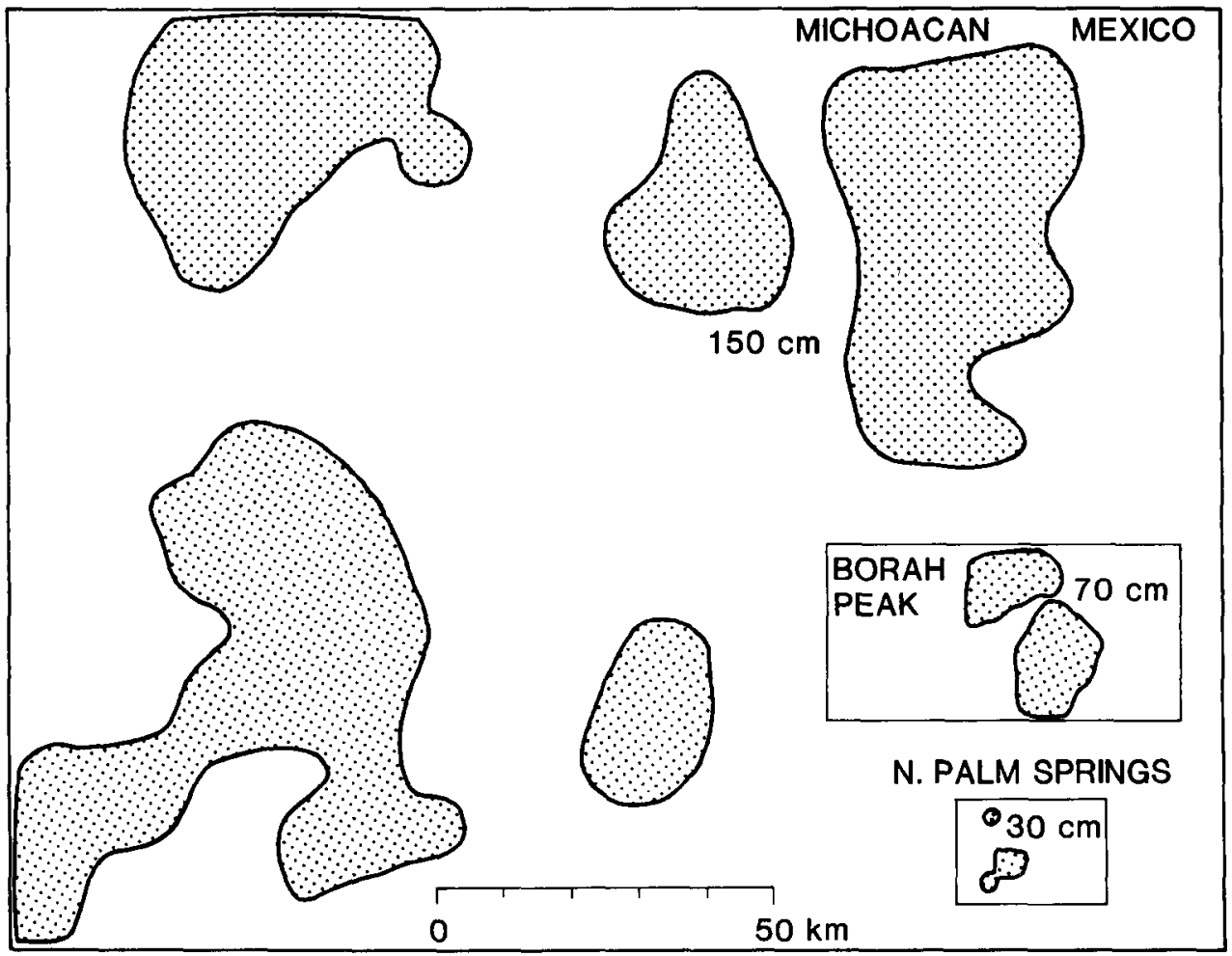

FIG. 10. Comparison of the asperity size observed for each of the three earthquakes examined in this study. The stippled areas denote regions where total slip was greater than 30 , 70 , and $150 \mathrm{~cm}$ for the North Palm Springs, Borah Peak, and Michaocan earthquakes, respectively. These regions are drawn at the same scale.

agation effects not accounted for in the inversion. For example, the near-source or near-receiver crustal structures that we use may not account for strong scattering effects that may dominate at the very short periods.

These observations imply that broadband signals can be extremely beneficial in the determination of earthquake source properties. Choy and Kind (1987) made a similar observation after inferring a complex rupture for the North Yemen earthquake of 13 December 1982 from reconstructed broadband waveforms derived from the GDSN short-period and long-period records. Broadband waveforms reconstructed from the GDSN data have the additional advantage of preserving proper timing of the $P$ waveforms, and a separate identification of short- and long-period arrivals is not necessary. In view of the difficulties encountered in modeling the short-period $P$ waveforms, the inversion of broadband data with the method employed in this study may require passband-filtering to remove those components at periods shorter than 1 or 2 sec.

\section{ACKNOWLEDGMENTS}

This research was conducted while C. Mendoza was under temporary assignment to the Pasadena Field Office at Caltech. We thank Bob Masse for arranging the visit and also the Pasadena personnel and staff for their support and assistance. In particular, Tom Heaton provided much useful discussion throughout the course of this work. Comments by Jim Dewey and George Choy, who reviewed the original manuscript, are also gratefully acknowledged. Additional reviews by C. Langston and an anonymous referee helped improve our presentation of the results. 


\section{ReFerenCes}

Archuleta, R. (1984). A faulting model for the 1979 Imperial Valley earthquake, J. Geophys. Res. 89, 4559-4585.

Boatwright, J. and G. L. Choy (1986). Teleseismic estimates of the energy radiated by shallow earthquakes, J. Geophys. Res. 91, 2095-2112.

Choy, G. L. and R. Kind (1987). Rupture complexity of a moderate-sized $\left(m_{b} 6.0\right)$ earthquake: broadband body-wave analysis of the North Yemen earthquake of 13 December 1982, Bull. Seism. Soc. Am. 77, 28-46.

Crone, A. J., M. N. Machette, M. G. Bonilla, J. J. Lienkaemper, K. L. Pierce, W. E. Scott, and R. C. Bucknam (1985). Characteristics of surface faulting accompanying the Borah Peak earthquake, central Idaho, in Proceedings of Workshop XXVIII on the Borah Peak, Idaho, Earthquake, U.S. Geol. Surv., Open-File Rept. 85-290, 43-58.

Der, Z. A., W. D. Rivers, T. W. McElfresh, A. O'Donnel, P. J. Klouda, and M. E. Marshall (1982). Worldwide variations in the attenuative properties of the upper mantle as determined from spectral studies of short-period body waves, Phys. Earth Planet. Interiors 30, 12-25.

Doser, D. I. and R. B. Smith (1985). Source parameters of the 28 October 1983 Borah Peak, Idaho, earthquake from body-wave analysis, Bull. Seism. Soc. Am. 75, 1041-1051.

Eissler, H., L. Astiz, and H. Kanamori (1986). Tectonic setting and source parameters of the September 19, 1985 Michoacan, Mexico earthquake, Geophys. Res. Letters 13, 569-572.

Ekstrom, G. and A. M. Dziewonski (1986). A very broad band analysis of the Michoacan, Mexico, earthquake of September 19, 1985, Geophys. Res. Letters 13, 605-608.

Eshelby, J. D. (1957). The determination of the elastic stress field of an ellipsoidal inclusion, and related problems, Proc. $R$. Soc. Lond., Ser. A 241, 376-396.

Grant, F. S. and G. F. West (1965). Interpretation Theory in Applied Geophysics, McGraw-Hill, New York.

Green, S. M. (1983). Seismotectonic study of the San Andreas, Mission Creek, and Banning fault systems, M.S. Thesis, University of California, Los Angeles, California.

Hadley, D. and H. Kanamori (1977). Seismic structure of the Transverse Ranges, California, Bull. Geol Soc. Am. 88, 1469-1478.

Hartzell, S. H. and T. H. Heaton (1983). Inversion of strong ground motion and teleseismic waveform data for the fault rupture history of the 1979 Imperial Valley, California, earthquake, Bull. Seism. Soc. Am. 73, 1553-1583.

Hartzell, S. H. and T. H. Heaton (1985). Teleseismic time functions for large, shallow subduction zone earthquakes, Bull. Seism. Soc. Am. 75, 965-1004.

Hartzell, S. H. and T. H. Heaton (1986). Rupture history of the 1984 Morgan Hill, California, earthquake from the inversion of strong motion records, Bull Seism. Soc. Am. 76, 649-674.

Hartzell, S. H., P. Spudich, and T. H. Heaton (1988). Comparison of seismic waveform inversion techniques for the rupture history of a finite fault with application to the 1986 North Palm Springs, California, earthquake (submitted for publication).

Heaton, T. H. (1982). The 1971 San Fernando earthquake: a double event? Bull. Seism. Soc. Am. 72, 2037-2062.

Houston, H. (1987). Source characteristics of large earthquakes at short periods, Ph.D. Thesis, California Institute of Technology, Pasadena, California.

Houston, H. and H. Kanamori (1986). Source characteristics of the 1985 Michoacan, Mexico earthquake at periods of 1 to 30 seconds, Geophys. Res. Letters 13, 597-600.

Jones, L. M., L. K. Hutton, D. D. Given, and C. R. Allen (1986). The North Palm Springs, California earthquake sequence of July 1986, Bull. Seism. Soc. Am. 76, 1830-1837.

Kikuchi, M. and H. Kanamori (1982). Inversion of complex body waves, Bull. Seism. Soc. Am. 72, 491-506.

Kikuchi, M. and Y. Fukao (1985). Iterative deconvolution of complex body waves from great earthquakes-The Tokachi-Oki earthquake of 1968, Phys. Earth. Planet. Interiors 37, 235-248.

Lawson, C. L. and R. J. Hanson (1974). Solving Least Squares Problems, Prentice-Hall, New Jersey.

Lay, T., H. Kanamori, and L. Ruff (1982). The asperity model and the nature of large subduction zone earthquakes, Earthquake Pred. Res. 1, 3-71.

Olson, A. H. and R. J. Apsel (1982). Finite faults and inverse theory with applications to the 1979 Imperial Valley earthquake, Bull. Seism. Soc. Am. 72, 1969-2001.

Pacheco, J. and J. Nábělek (1986). Source mechanisms of three moderate southern California earthquakes of July 1986 (abstract), EOS 67, 963. 
Pacheco, J. and J. Nábělek (1988). Source mechanisms of three moderate California earthquakes of July, 1986 (submitted for publication).

Priestley, K. F. and T. G. Masters (1986). Source mechanism of the September 19, 1985, Michoacan earthquake and its implications, Geophys. Res. Letters 13, 601-604.

Richins, W. D., J. C. Pechmann, R. B. Smith, C. J. Langer, S. K. Goter, J. E. Zollweg, and J. J. King (1987). The 1983 Borah Peak, Idaho, earthquake and its aftershocks, Bull. Seism. Soc. Am. 77, 694-723.

Riedesel, M. A., T. H. Jordan, A. F. Sheehan, and P. G. Silver (1986). Moment-tensor spectra of the 19 Sept 85 and 21 Sept 85 Michoacan, Mexico, earthquakes, Geophys. Res. Letters 13, 609-612.

Ruff, L. and H. Kanamori (1983). The rupture process and asperity distribution of three great earthquakes from long-period diffracted $P$-waves, Phys. Earth Planet. Interiors 31, 202-230.

Stolte, C., K. C. McNally, J. Gonzalez-Ruiz, G. W. Simila, A. Reyes, C. Rebollar, L. Munguia, and L. Mendoza (1986). Fine structure of a post-failure Wadati-Benioff zone, Geophys. Res. Letters 13, 577-580.

Ward, S. N. and S. E. Barrientos (1986). An inversion for slip distribution and fault shape from geodetic observations of the 1983 Borah Peak, Idaho, earthquake, J. Geophys. Res. 91, 4909-4919.

Yoshida, S. (1986). A method of waveform inversion for earthquake rupture process, J. Phys. Earth 34, 235-255.

U.S. Geological Survey

National Earthquake Information Center

Box 25046, MS 967

Denver, Colorado 80225 (C.M.)

Manuscript received 8 August 1987
U.S. Geological Survey

Seismological Laboratory (252-21)

California Institute of Technology

Pasadena, California 91125 (S.H.H.) 